\title{
Enhanced macrophage tropism of HIV in brain and lymphoid tissues is associated with sensitivity to the broadly neutralizing CD4 binding site antibody bI 2 Rebecca L Dunfee ${ }^{1,2}$, Elaine R Thomas ${ }^{1,2}$ and Dana Gabuzda*1,3
}

\author{
Address: ${ }^{1}$ Department of Cancer Immunology and AIDS, Dana Farber Cancer Institute, Boston MA, USA, ${ }^{2}$ Department of Pathology, Harvard \\ Medical School, Boston MA, USA and ${ }^{3}$ Department of Neurology, Harvard Medical School, Boston MA, USA \\ Email: Rebecca L Dunfee - dunfeer@niaid.nih.gov; Elaine RThomas - EThomas@arrowt.co.uk; \\ Dana Gabuzda* - dana_gabuzda@dfci.harvard.edu \\ * Corresponding author
}

Published: 20 July 2009

Retrovirology 2009, 6:69 doi:10.1 186/1742-4690-6-69

This article is available from: http://www.retrovirology.com/content/6/I/69

(C) 2009 Dunfee et al; licensee BioMed Central Ltd.

This is an Open Access article distributed under the terms of the Creative Commons Attribution License (http://creativecommons.org/licenses/by/2.0), which permits unrestricted use, distribution, and reproduction in any medium, provided the original work is properly cited.

\begin{abstract}
Macrophages in the central nervous system (CNS) and other tissues are an important cellular reservoir for human immunodeficiency virus type I (HIV) infection, particularly in the later stages of disease. Macrophage-tropic HIV strains have an enhanced capacity to enter cells expressing low levels of CD4 through mechanisms that are not well understood. Here, we use a panel of primary HIV envelopes from brain and lymphoid tissues to examine the relationship between neutralization sensitivity to reagents targeting the CD4 binding site and virus entry into macrophages. Neutralization assays using pseudotyped viruses showed an association between the capacity of HIV to enter macrophages and increased sensitivity to the broadly neutralizing monoclonal antibody (mAb) b/2, which recognizes a conserved epitope overlapping the CD4 binding site, but not sensitivity to soluble CD4 (sCD4) or b6, a non-neutralizing CD4 binding site mAb. Furthermore, loss of an $\mathrm{N}$-linked glycosylation site at position 386 in the $\mathrm{V} 4$ region of Env enhanced macrophage tropism together with b 12 sensitivity, but not neutralization by sCD 4 , b6, or a broadly neutralizing AIDS patient serum. These findings suggest that exposure of the $b / 2$ epitope, rather than exposure of the CD4 binding site per se, enhances HIV macrophage tropism, possibly by exposing a region on the outer domain of gP I 20 that is initially recognized by CD4. These findings suggest overlap between specific gp/20 determinants in or near the b/2 epitope and those conferring macrophage tropism.
\end{abstract}

\section{Background}

Human immunodeficiency virus type 1 (HIV) infects tissue macrophages, microglia, and other mononuclear phagocytes, which represent an important cellular reservoir for viral replication and persistence in brain and other macrophage-rich tissues (i.e., lung, gut, and bone marrow) [1-3]. HIV entry into cells is initiated by interaction between the envelope glycoprotein (Env) surface sub- unit gp120 and CD4, which induces a conformational change in gp120 that exposes the coreceptor binding site [4]. The interaction of CD4-bound gp120 with a coreceptor, usually CCR5 or CXCR4, triggers conformational changes in gp120 and the transmembrane subunit gp41 that enable fusion and virus entry. CCR5 is the primary coreceptor used for infection of macrophages [4-7]. CCR5 usage is neither necessary nor sufficient for macrophage 
tropism [8], however, suggesting that determinants other than those that specify coreceptor usage influence the capacity of HIV to replicate in macrophages.

Macrophages express lower levels of CD4 compared to CD4+ T-lymphocytes. Previous studies demonstrated that HIV macrophage tropism is associated with an enhanced capacity to use low levels of CD4 for fusion and entry [914]. We previously identified amino acid variants in the HIV Env that increase viral tropism for macrophages by enhancing gp120-CD4 affinity (N283 in the C2 region) or exposure of the CD4 binding site (loss of an N-linked glycosylation site at position 386 in the V4 region) $[9,10]$. However, HIV can also acquire an enhanced ability to enter macrophages by additional mechanisms that are not well defined.

The HIV envelope glycoproteins are the primary target for neutralizing antibodies in vivo $[15,16]$. The antibody response to acute HIV infection develops rapidly, and evolves concurrently with viral diversity during the course of disease, exerting strong selection pressure on viral evolution and leading to emergence of neutralization-resistant HIV variants $[17,18]$. The ability to generate neutralizing antibodies diminishes during disease progression, reflecting progressive loss of CD4 T-cell help and B-cell dysfunction.

HIV isolates that replicate efficiently in macrophages and microglia frequently exhibit increased sensitivity to neutralizing antibodies $[11-13,19,20]$. Consistent with these findings, a simian-human immunodeficiency virus (SHIV) isolated from infected rhesus macaques with neurological disease exhibited enhanced macrophage tropism together with increased sensitivity to neutralizing antibodies [21]. The HIV Env amino acid variant D386, which eliminates an $\mathrm{N}$-linked glycosylation site and increases exposure of the conserved broadly neutralizing monoclonal antibody (mAb) b12 epitope overlapping the CD4 binding site, also enhances HIV macrophage tropism $[10,22,23]$. Previous studies reported that HIV macrophage tropism correlates with increased neutralization sensitivity to mAbs and other reagents that block EnvCD4 interactions but not with sensitivity to other entry inhibitors [22,23]. Collectively, these findings suggest that an association between enhanced HIV entry into macrophages and increased sensitivity to reagents targeting the $\mathrm{CD} 4$ binding site.

Here, we use a panel of viruses expressing primary HIV Envs from brain and lymphoid tissues $[9,10,14]$ to further examine the association between neutralization sensitivity to reagents targeting the CD4 binding site and macrophage tropism. The capacity of HIV to enter macrophages correlated with neutralization sensitivity to the CD4 bind- ing site mAb b12 and a broadly neutralizing HIV-infected patient serum, but not sensitivity to soluble CD4 (sCD4) or mAb b6, another mAb that targets the CD4 binding site. The loss of an N-linked glycosylation site at position 386 enhanced macrophage tropism together with sensitivity to mAb b12, but not sensitivity to $\mathrm{SCD} 4, \mathrm{mAb} b 6$, or HIV-infected patient serum. These findings suggest that exposure of the b12 epitope overlapping the $\mathrm{CD} 4$ binding site, rather than exposure of the CD4 binding site per se, enhances HIV macrophage tropism, possibly by exposing a region on the outer domain of gp120 that is initially recognized by CD4.

\section{Findings}

We previously demonstrated that loss of an N-linked glycosylation site at position 386 in the $\mathrm{V} 4$ region of primary HIV Envs increases exposure of the b12 epitope and enhances macrophage tropism [10]. To better understand the relationship between macrophage tropism and sensitivity to reagents targeting the CD4 binding site, we used a panel of viruses containing CCR5-tropic (R5) primary HIV Envs cloned directly from brain and lymphoid tissues $[9,10,14]$ to determine neutralization sensitivity to sCD4 and mAbs b12 and b6, which recognize neutralizing and non-neutralizing epitopes overlapping the CD4 binding site [24], respectively, and a broadly-neutralizing HIVinfected patient serum (Table 1). Env genes cloned into pCR3.1 from primary virus isolates or autopsy brain and lymphoid tissues from AIDS patients with HIV-associated dementia (HAD) were described previously $[9,14,19]$. HIV luciferase reporter viruses were generated by cotransfection of 293T cells with an HIV provirus with env deleted and nef replaced by luciferase (pNL4-3envluc,) and pCR3.1-Env as described [19]. Cf2 cells [19] used as target cells for neutralization assays were cotransfected with pcDNA3-CD4 and pcDNA3-CCR5. HIV luciferase reporter viruses were incubated with a range of concentrations of human monoclonal Abs (mAbs), soluble CD4 (sCD4; Immunodiagnostics, Inc., Woburn, MA), or a broadly neutralizing HIV-1 serum (HIV-1 neutralizing serum (serum 2; [25]) obtained from L. Vujcic through the AIDS Research and Reference Reagent Program) $1 \mathrm{~h}$ prior to infection of Cf2 cells transiently expressing CD4 and CCR5. Cells were harvested $48 \mathrm{~h}$ post infection and assayed for luciferase activity.

Viruses pseudotyped with HIV Envs that mediate high levels of entry into macrophages had increased sensitivity to mAb b12 and the HIV-infected patient serum compared to viruses expressing Envs that mediate low levels of entry in macrophages (Figure 1A, C, D, F; A and 1C, R = -0.5944, $\mathrm{p}=0.0093$ and $\mathrm{R}=-0.5021, \mathrm{p}=0.034$, respectively, Spearman correlation; $1 \mathrm{D}$ and $1 \mathrm{~F}, \mathrm{p}=0.022$ and 0.034 , respectively, Mann-Whitney test). In contrast, sensitivity to sCD4 or the non-neutralizing mAb b6 did not correlate 
Table I: Neutralization sensitivity of primary HIV-I Envs with variable macrophage tropism to gp I 20 mAbs, soluble CD4, and a broadly neutralizing HIV-infected patient serum

\begin{tabular}{|c|c|c|c|c|c|c|c|}
\hline Patient & Tissue $^{a}$ & Env clone & MDM entry & $\mathrm{b} / 2 \mathrm{IC}_{50} \mathrm{c}$ & $\mathrm{b} 6 \mathrm{IC}_{50} \mathrm{c}$ & $\mathrm{sCD} 4 \mathrm{IC}_{50} \mathrm{c}$ & $P S I C_{50}{ }^{c}$ \\
\hline \multirow[t]{4}{*}{ MACS2 } & $\mathrm{FL}$ & $8-12$ & 35478 & 3.37 & $>20$ & 1.03 & 80.9 \\
\hline & & $9-15$ & 1765 & 1.15 & $>20$ & 0.22 & 76.4 \\
\hline & LN & $10-15$ & $1300 \mid$ & 0.99 & $>20$ & $>20$ & $<50$ \\
\hline & SP & $6-18$ & 59224 & 10.89 & $>20$ & $>20$ & $<50$ \\
\hline \multirow[t]{4}{*}{ MACS3 } & $\mathrm{FL}$ & $12-27$ & 13810 & $>20$ & 1.87 & 1.10 & $<50$ \\
\hline & & 5 & 3402 & $>20$ & 6.78 & 0.40 & $<50$ \\
\hline & LN & 2 & 1957 & $>20$ & $>20$ & 3.22 & $<50$ \\
\hline & & 20 & 16658 & $>20$ & $>20$ & $>20$ & $<50$ \\
\hline \multirow[t]{3}{*}{ UKI } & $\mathrm{FL}$ & $2-13 b$ & 4378 & 0.05 & $>20$ & 5.44 & $<50$ \\
\hline & SP & $6-20$ & 812689 & 0.03 & $>20$ & 2.39 & 124.2 \\
\hline & & 20 & 35723 & 0.03 & $>20$ & 0.27 & 230.2 \\
\hline \multirow[t]{4}{*}{ UK7 } & $\mathrm{FL}$ & $6-24$ & 9659 & 5.53 & $>20$ & 7.68 & 145 \\
\hline & & $1-4$ & 13207 & 11.37 & $>20$ & $>20$ & 128 \\
\hline & isolate & br34 & 496588 & 0.26 & $>20$ & 0.45 & 332.2 \\
\hline & LN & $7-6$ & 5260 & 5.55 & $>20$ & $>20$ & $<50$ \\
\hline \multirow[t]{4}{*}{ controls } & & YU2 & 38052 & 5.47 & $>20$ & 1.14 & 72.4 \\
\hline & & YU2 N386D & I|4755 & 2.79 & $>20$ & 0.45 & 115.2 \\
\hline & & JRFL & 215305 & 0.18 & $>20$ & 3.72 & 107.3 \\
\hline & & JRFL N386D & 320642 & 0.09 & $>20$ & 6.05 & 92.7 \\
\hline
\end{tabular}

a FL, frontal lobe (brain); LN, lymph node; SP, spleen

b Luciferase activity in monocyte-derived macrophages (MDM) infected with pseudotyped luciferase-expressing reporter viruses [I0, I4].

${ }^{c} \mathrm{mAb}(\mu \mathrm{g} / \mathrm{ml})$, soluble CD4 (sCD4; $\left.\mu \mathrm{g} / \mathrm{ml}\right)$, or HIV-infected patient serum (PS; reciprocal serum dilution) concentration at which luciferase expression was reduced by $50 \%$ compared to infection in the absence of $\mathrm{mAb}\left(\mathrm{IC}_{50}\right)$.

with levels of HIV entry into macrophages (Figure 1B, E, p $=0.9141$; and data not shown). Furthermore, there was no correlation between neutralization sensitivity to mAb b12 and neutralization sensitivity to $\operatorname{sCD} 4(\mathrm{p}=0.3279$; Additional file 1). These results suggest that macrophage tropism is associated with increased sensitivity to mAb b12, but not sensitivity to sCD4 or the non-neutralizing CD4 binding site mAb b6. Thus, macrophage tropism was associated with increased exposure of the b12 epitope overlapping the CD4 binding site, rather than exposure of the CD4 binding site per se.

Elimination of an N-linked glycan at position 386 in the macrophage-tropic primary HIV Envs YU2 and JRFL enhances entry into macrophages by $200 \%$ and $49 \%$, respectively (Table 1 , Figure $2 \mathrm{~A}$ and [10]). To determine whether removal of the N-linked glycan at position 386 also influences sensitivity to b12 or other reagents that target the CD4 binding site, we investigated neutralization of viruses expressing YU2 and JRFL wild-type and N386D mutant Envs with mAbs b12 and b6, sCD4 and the broadly neutralizing HIV-infected patient serum. The N386D change in both YU2 and JRFL resulted in a 2-fold increase in sensitivity to neutralization by mAb b12 compared to that of the wild-type parental Envs (Table 1 and Figure 2B). The N386D change in YU2 resulted in increased sensitivity to sCD4, whereas the N386D change in JRFL decreased SCD4 sensitivity compared to the wildtype parental Envs (Table 1 and Figure 2C). YU2 and JRFL wild-type and N386D mutant viruses had similar sensitivities to neutralization by mAb b6 and the HIV-infected patient serum (Table 1, Figure 2D, and data not shown). These results are consistent with our previous study in which the reverse mutation D386N, which restored the Nlinked glycan at position 386 in the macrophage-tropic UK1br and Macs2br13 Envs, decreased sensitivity to neutralization by mAb b12 along with replication in macrophages [10].

Our findings demonstrate an association between the capacity of HIV to enter macrophages (i.e., macrophage tropism) and neutralization sensitivity to the CD4 binding site mAb b12, but not sensitivity to the non-neutralizing $\mathrm{mAb}$ b6 or sCD4. Furthermore, we show that loss of an N-linked glycosylation site at position 386 in the macrophage-tropic HIV YU2 and JRFL Envs enhances macrophage tropism along with neutralization sensitivity to b12, but not neutralization sensitivity to sCD4, b6, or a broadly neutralizing AIDS patient serum. These findings suggest overlap between specific gp120 determinants in or near the b12 epitope and those conferring macrophage tropism.

CD4, b12, and b6 have overlapping binding sites on gp120 [24,26]. The b12 mAb recognizes a conserved epitope on the neutralizing face of gp120 overlapping the CD4 binding site, while b6 recognizes a different epitope that partially overlaps the binding sites for b12 and CD4 

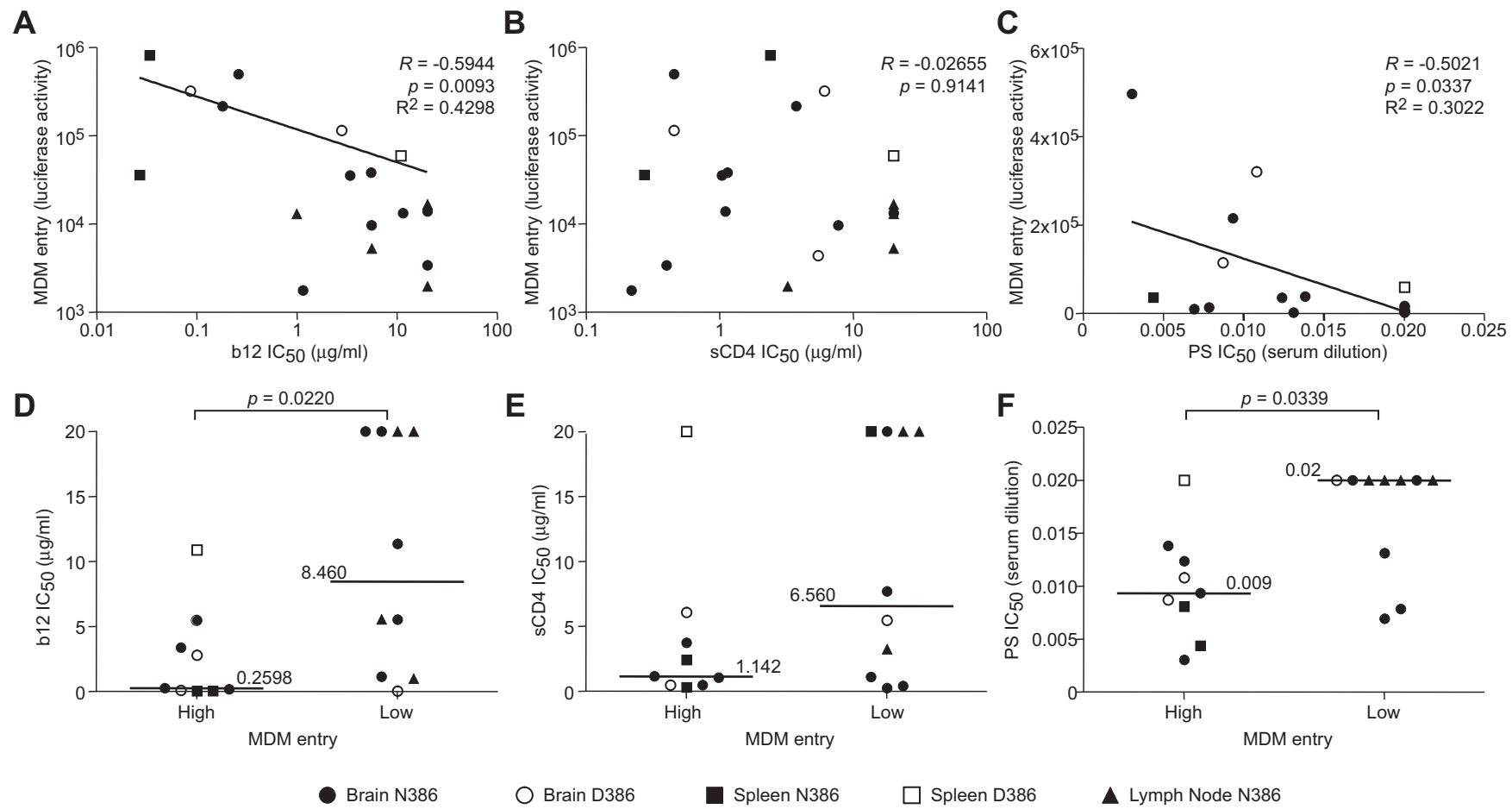

Brain N386 O Brain D386

Figure I

Enhanced HIV entry into macrophages is associated with sensitivity to neutralizing $\mathrm{mAb} b \mid \mathbf{2}$ and a broadly neutralizing HIV-infected patient serum. HIV luciferase reporter viruses pseudotyped with primary HIV Envs cloned directly from brain, spleen, or lymph node tissues from AIDS patients with HAD were incubated with a range of concentrations of human mAb bI2 ( $A$ and $D$ ), soluble CD4 (sCD4; $B$ and $E$ ), or HIV-I neutralizing patient serum (PS; C and F) I h prior to infection of $C f 2$ cells transiently expressing CD4 and CCR5. Cells were harvested $48 \mathrm{~h}$ post infection and assayed for luciferase activity. (A, B, C) The concentrations at which luciferase expression was reduced by $50 \%$ compared to infection in the absence of $\mathrm{mAb}\left(\mathrm{IC}_{50}\right)$ were calculated and plotted as a function of MDM entry [I0, I4]. $R$ and $p$ values were determined by Spearman correlation. (D, E, F) bI2, sCD4, and PS IC50s of HIV Envs with low to intermediate MDM infectivity (< median; median $=16,658$ relative luciferase units) were compared to Envs with intermediate to high MDM infectivity ( $>$ median). Monocyte-derived macrophages (MDM) were isolated from peripheral blood mononuclear cells from healthy HIV-I-negative donors by plastic adherence and cultured in RPMI 1640 medium supplemented with $10 \%$ FBS, and $10 \mathrm{ng} / \mathrm{ml}$ macrophage colony stimulating factor (M-CSF) [8]. The MDM entry and sequence data were reported previously [10,14]. Env clones containing either the N386 or D386 variant are indicated by closed and open symbols, respectively. MDM were prepared as above in 48well plates and infected with $2 \times 10^{4} 3 \mathrm{H}$ cpm RT units of Env pseudotyped virus stock. Cells were lysed 6 days post-infection and assayed for luciferase activity. Significant differences between groups $(p<0.05$, Mann-Whitney test) are indicated by a $*$.

[24]. The initial Env-CD4 interaction readily dissociates, and conformational changes in Env induced by CD4 binding increase the stability of the Env-CD4 complex before subsequent structural rearrangements allow coreceptor binding $[26,27]$. b12 contact occurs at the exposed surface on the outer domain of gp120 that is initially recognized by CD4 [26]. Furthermore, b12 is the only antibody that targets the CD4 binding site and also recognizes Env in the CD4-bound, stabilized conformation adopted before coreceptor binding [26]. These observations support the idea that exposure of the b12 epitope enhances HIV entry into macrophages, which express low levels of CD4 compared to T-cells, possibly by exposing a region on the outer domain of gp120 initially recognized by CD4.

The loss of a glycosylation site at HIV Env position 386 increases exposure of the b12 epitope $[10,22,28]$, probably due to loss of steric hindrance, and also enhances macrophage tropism in a strain-dependent manner [10]. Loss of a glycosylation site at 386 does not predict b1 2 sensitivity $[10,22,28]$, however, suggesting that other Env determinants influence exposure of the b12 epitope. DuenasDecamp et al. showed that an arginine at position 373 in the $\mathrm{C} 3$ region, proximal to the CD4 binding site, increased resistance to b12 neutralization [22]. However, the HIV 


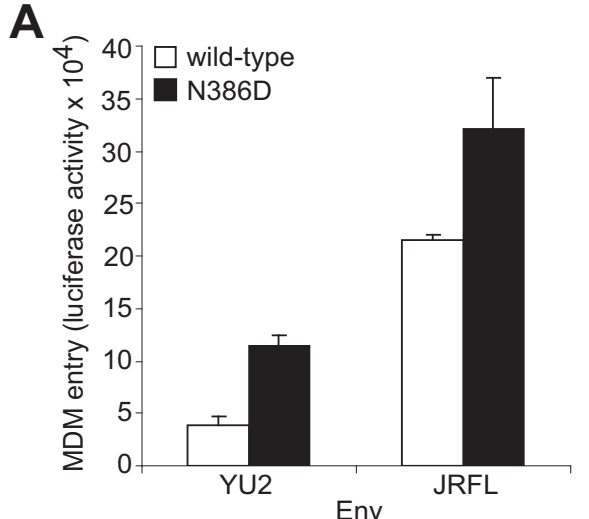

B
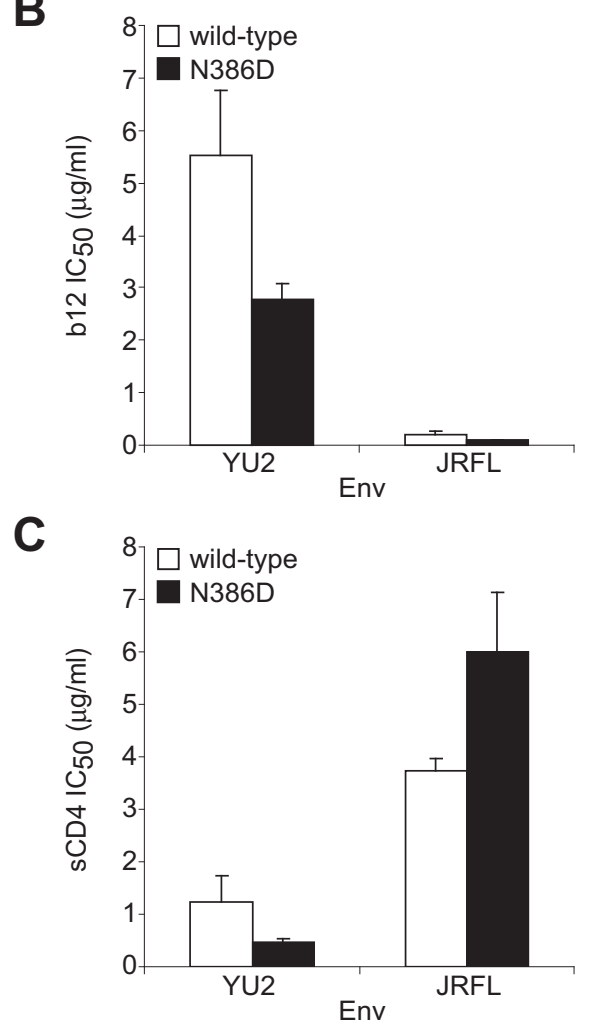

D

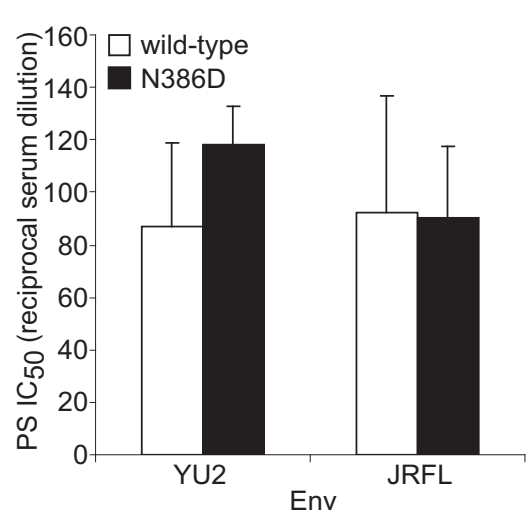

Figure 2

\section{Figure 2}

Loss of an $\mathbf{N}$-linked glycan at position 386 in primary HIV Envs enhances macrophage tropism and neutralization sensitivity to mAb bI 2. (A) MDM were infected with luciferase-expressing reporter viruses expressing wild-type or N386D mutant Envs. Cells were lysed 6 days post-infection and analyzed for luciferase activity. (B, C, D) Luciferase-expressing reporter viruses expressing wild-type or N386D mutant Envs were incubated with a range of concentrations of human mAb bI 2 (B), sCD4 (C), or a HIV-I neutralizing patient serum (PS; D) I h prior to infection of Cf2 cells transiently expressing CD4 and CCR5. Cells were harvested $48 \mathrm{~h}$ post infection and assayed for luciferase activity. Data are expressed as the concentrations at which luciferase expression was reduced by $50 \%$ compared to infection in the absence of $\mathrm{mAb}\left(\mathrm{IC}_{50}\right)$. Error bars represent standard deviations.

Envs in the present study all have methionine or threonine at position 373, and b12 neutralization did not correlate with amino acid differences at this position (data not shown). Thus, the influence of amino acid changes at position 373 on exposure of the b12 epitope is highly strain-dependent.

We found that a majority of macrophage-tropic HIV Envs are sensitive to b12 neutralization. A recent study demonstrated that early transmitted HIV variants replicate in Tcells but have relatively low capacity to replication in MDM [29]. HIV viruses isolated from late-stage AIDS patients have enhanced macrophage tropism together with increased neutralization sensitivity to b12 compared to viruses isolated from asymptomatic HIV-infected individuals [30]. Anti-CD4 binding site antibodies are generated after HIV infection, and can be detected in most HIVinfected individuals [31-33]. Broader and more potent neutralizing antibody responses are often due to the presence of neutralizing antibodies targeting the CD4 binding site [31-33]. However, only rare individuals develop broadly neutralizing anti-CD4 binding site antibodies, so b12-like antibodies are uncommon in HIV-infected patients. The neutralizing activity of sera from long-term nonprogressors is partially attributable to the presence of antibodies that target the CD4 binding site [32,34], suggesting these antibodies may play a role in controlling viral replication in vivo. Neutralizing antibody responses that target the b12 binding site may exert negative selection pressure against macrophage-tropic HIV variants until the later stages of HIV disease. The brain may be a site for emergence and persistence of neutralization-sensitive macrophage-tropic HIV variants, particularly in the setting of a weak humoral immune response $[35,36]$. 
In conclusion, macrophage-tropic HIV strains play a role in the establishing long-lived cellular reservoirs in macrophage-rich tissues that include brain, lung, gut, and bone marrow [1-3]. Furthermore, macrophages are the principal source of virus after CD4+ T cells are depleted [37]. In this study, we demonstrate an association between HIV macrophage tropism and neutralization sensitivity to the $\mathrm{CD} 4$ binding site mAb b12. In contrast, there was no association with neutralization sensitivity to the non-neutralizing CD4 binding site mAb b6 or sCD4. These findings suggest overlap between specific gp120 determinants that increase exposure of the b12 epitope and those conferring macrophage tropism. Future studies will be important to better understand immune selection pressures that drive HIV evolution towards variants with enhanced macrophage tropism, and the role of neutralizing antibodies that target the CD4 binding site in these processes.

\section{Competing interests}

The authors declare that they have no competing interests.

\section{Authors' contributions}

R.L.D. and D.G. designed research; R.L.D. and E.R.T performed research; R.L.D. and D.G. analyzed data; and R.L.D. and D.G. wrote the paper.

\section{Additional material}

\section{Additional file 1}

Supplementary Figure. HIV Env neutralization sensitivity to $m A b$ b12 does not correlate neutralization sensitivity to sCD4. HIV luciferase reporter viruses were incubated with a range of concentrations of human $m A b$ b12 or $s C D 41 \mathrm{~h}$ prior to infection of $C f 2$ cells transiently expressing CD4 and CCR5. Cells were harvested $48 \mathrm{~h}$ post infection and assayed for luciferase activity. Data are expressed as the concentrations at which luciferase expression was reduced by 50\% compared to infection in the absence of $m A b$ or $s C D 4\left(I C_{50}\right)$. (A) $s C D 4 I C_{50}$ were plotted as a function of b12 $I C_{50}$ s. $R$ and p values, Spearman correlation. (B) $s C D 4 I C_{50} s$ of HIV Envs with low to intermediate b12 sensitivity ( $<$ median; median $=3.374 \mu \mathrm{g} / \mathrm{ml}$ ) were compared to Envs with intermediate to high b12 sensitivity (> median). p values, Mann-Whitney test.

Click here for file

[http://www.biomedcentral.com/content/supplementary/17424690-6-69-S1.pdf]

\section{Acknowledgements}

We thank Dennis Burton (Scripps) for providing the b 12 and b 6 antibodies. This work was supported by $\mathrm{NIH}$ grant MH83588. Core facilities were supported by Harvard University Center for AIDS Research and DFCI/Harvard Cancer Center grants.

\section{References}

I. Gorry PR, Churchill M, Crowe SM, Cunningham AL, Gabuzda D: Pathogenesis of macrophage tropic HIV-I. Curr HIV Res 2005, 3:53-60.

2. Pierson T, McArthur J, Siliciano RF: Reservoirs for HIV-I: mechanisms for viral persistence in the presence of antiviral immune responses and antiretroviral therapy. Annu Rev Immunol 2000, 1 8:665-708.

3. Wang TH, Donaldson YK, Brettle RP, Bell JE, Simmonds P: Identification of shared populations of human immunodeficiency virus type I infecting microglia and tissue macrophages outside the central nervous system. J Virol 200I, 75: I I686-I I699.

4. Doms RW: Beyond receptor expression: the influence of receptor conformation, density, and affinity in HIV-I infection. Virology 2000, 276:229-237.

5. Berger EA, Murphy PM, Farber JM: Chemokine receptors as HIVI coreceptors: roles in viral entry, tropism, and disease. Annu Rev Immunol 1999, I 7:657-700.

6. Clapham PR, McKnight A: Cell surface receptors, virus entry and tropism of primate lentiviruses. J Gen Virol 2002, 83:1809-1829.

7. Moore JP, Kitchen SG, Pugach P, Zack JA: The CCR5 and CXCR4 coreceptors - central to understanding the transmission and pathogenesis of human immunodeficiency virus type I infection. AIDS Res Hum Retroviruses 2004, 20: I I I-I 26.

8. Gorry PR, Bristol G, Zack JA, Ritola K, Swanstrom R, Birch CJ, Bell JE, Bannert N, Crawford K, Wang H, et al.: Macrophage tropism of human immunodeficiency virus type I isolates from brain and lymphoid tissues predicts neurotropism independent of coreceptor specificity. J Virol 200I, 75:10073-10089.

9. Dunfee RL, Thomas ER, Gorry PR, Wang J, Taylor J, Kunstman K, Wolinsky SM, Gabuzda D: The HIV Env variant N283 enhances macrophage tropism and is associated with brain infection and dementia. Proc Natl Acad Sci USA 2006, 103: I5 I60-15165.

10. Dunfee RL, Thomas ER, Wang J, Kunstman K, Wolinsky SM, Gabuzda $D$ : Loss of the $\mathbf{N}$-linked glycosylation site at position 386 in the HIV envelope V4 region enhances macrophage tropism and is associated with dementia. Virology 2007, 367:222-234.

II. Martin J, LaBranche CC, Gonzalez-Scarano F: Differential CD4/ CCR5 utilization, gp I 20 conformation, and neutralization sensitivity between envelopes from a microglia-adapted human immunodeficiency virus type I and its parental isolate. J Virol 200I, 75:3568-3580.

12. Martin-Garcia J, Cao W, Varela-Rohena A, Plassmeyer ML, GonzalezScarano F: HIV-I tropism for the central nervous system: Brain-derived envelope glycoproteins with lower CD4 dependence and reduced sensitivity to a fusion inhibitor. Virology 2006, 346:169-179.

13. Peters PJ, Bhattacharya J, Hibbitts S, Dittmar MT, Simmons G, Bell J, Simmonds P, Clapham PR: Biological analysis of human immunodeficiency virus type I R5 envelopes amplified from brain and lymph node tissues of AIDS patients with neuropathology reveals two distinct tropism phenotypes and identifies envelopes in the brain that confer an enhanced tropism and fusigenicity for macrophages. J Virol 2004, 78:69I5-6926.

14. Thomas ER, Dunfee RL, Stanton J, Bogdan D, Taylor J, Kunstman K, Bell JE, Wolinsky SM, Gabuzda D: Macrophage entry mediated by HIV Envs from brain and lymphoid tissues is determined by the capacity to use low CD4 levels and overall efficiency of fusion. Virology 2007, 360:105-II9.

15. Burton DR, Desrosiers RC, Doms RW, Koff WC, Kwong PD, Moore JP, Nabel G], Sodroski J, Wilson IA, Wyatt RT: HIV vaccine design and the neutralizing antibody problem. Nat Immunol 2004, 5:233-236.

16. Pantophlet R, Burton DR: GP I 20: target for neutralizing HIV-I antibodies. Annu Rev Immunol 2006, 24:739-769.

17. Richman DD, Wrin T, Little S), Petropoulos C): Rapid evolution of the neutralizing antibody response to HIV type I infection. Proc Natl Acad Sci USA 2003, I 00:4 |44-4I49.

18. Wei X, Decker JM, Wang S, Hui H, Kappes JC, Wu X, SalazarGonzalez JF, Salazar MG, Kilby JM, Saag MS, et al.: Antibody neutralization and escape by HIV-I. Nature 2003, 422:307-3I 2.

19. Gorry PR, Taylor J, Holm GH, Mehle A, Morgan T, Cayabyab M, Farzan M, Wang H, Bell JE, Kunstman K, et al.: Increased CCR5 affinity and reduced CCR5/CD4 dependence of a neurovirulent primary human immunodeficiency virus type I isolate. J Virol 2002, 76:6277-6292.

20. Van Marle G, Rourke SB, Zhang K, Silva C, Ethier J, Gill MJ, Power C: HIV dementia patients exhibit reduced viral neutralization and increased envelope sequence diversity in blood and brain. Aids 2002, 16:1905-1914. 
21. Song B, Cayabyab M, Phan N, Wang L, Axthelm MK, Letvin NL, Sodroski JG: Neutralization sensitivity of a simian-human immunodeficiency virus (SHIV-HXBC2P 3.2N) isolated from an infected rhesus macaque with neurological disease. Virology 2004, 322: I68-18I.

22. Duenas-Decamp MJ, Peters P, Burton D, Clapham PR: Natural resistance of human immunodeficiency virus type $I$ to the CD4bs antibody bI 2 conferred by a glycan and an arginine residue close to the CD4 binding loop. J Virol 2008, 82:5807-58|4.

23. Peters PJ, Duenas-Decamp MJ, Sullivan WM, Brown R, Ankghuambom C, Luzuriaga K, Robinson J, Burton DR, Bell J, Simmonds P, et al: Variation in HIV-I R5 macrophage-tropism correlates with sensitivity to reagents that block envelope: CD4 interactions but not with sensitivity to other entry inhibitors. Retrovirology 2008, 5:5.

24. Pantophlet R, Ollmann Saphire E, Poignard P, Parren PW, Wilson IA, Burton DR: Fine mapping of the interaction of neutralizing and nonneutralizing monoclonal antibodies with the CD4 binding site of human immunodeficiency virus type I gp I 20. J Virol 2003, 77:642-658.

25. Vujcic LK, Quinnan GV Jr: Preparation and characterization of human HIV type I neutralizing reference sera. AIDS Res Hum Retroviruses 1995, I I:783-787.

26. Zhou T, Xu L, Dey B, Hessell AJ, Van Ryk D, Xiang SH, Yang X, Zhang MY, Zwick MB, Arthos J, et al.: Structural definition of a conserved neutralization epitope on HIV-I gp I20. Nature 2007, 445:732-737.

27. Chang MI, Panorchan P, Dobrowsky TM, Tseng Y, Wirtz D: Singlemolecule analysis of human immunodeficiency virus type I gpl20-receptor interactions in living cells. J Virol 2005, 79:|4748-|4755.

28. Sanders RW, van Anken E, Nabatov AA, Liscaljet IM, Bontjer I, Eggink D, Melchers M, Busser E, Dankers MM, Groot F, et al: The carbohydrate at asparagine 386 on HIV-I gp I 20 is not essential for protein folding and function but is involved in immune evasion. Retrovirology 2008, 5:10.

29. Salazar-Gonzalez JF, Salazar MG, Keele BF, Learn GH, Giorgi EE, Li H, Decker JM, Wang S, Baalwa J, Kraus MH, et al.: Genetic identity, biological phenotype, and evolutionary pathways of transmitted/founder viruses in acute and early HIV-I infection. J Exp Med 2009, 206: I 273-I289.

30. Gray L, Sterjovski J, Churchill M, Ellery P, Nasr N, Lewin SR, Crowe SM, Wesselingh SL, Cunningham AL, Gorry PR: Uncoupling coreceptor usage of human immunodeficiency virus type I (HIVI) from macrophage tropism reveals biological properties of CCR5-restricted HIV-I isolates from patients with acquired immunodeficiency syndrome. Virology 2005, 337:384-398.

31. Binley JM, Lybarger EA, Crooks ET, Seaman MS, Gray E, Davis KL, Decker JM, Wycuff D, Harris L, Hawkins N, et al.: Profiling the specificity of neutralizing antibodies in a large panel of plasmas from patients chronically infected with human immunodeficiency virus type I subtypes B and C. J Virol 2008, 82:1165I-11668.

32. Li Y, Migueles SA, Welcher B, Svehla K, Phogat A, Louder MK, Wu X, Shaw GM, Connors M, Wyatt RT, Mascola JR: Broad HIV-I neutralization mediated by CD4-binding site antibodies. Nat Med 2007, I3:1032-1034.

33. Sather DN, Armann J, Ching LK, Mavrantoni A, Sellhorn G, Caldwell Z, Yu X, Wood B, Self S, Kalams S, Stamatatos L: Factors associated with the development of cross-reactive neutralizing antibodies during human immunodeficiency virus type I infection. J Virol 2009, 83:757-769.

34. Li Y, Svehla K, Louder MK, Wycuff D, Phogat S, Tang M, Migueles SA, Wu X, Phogat A, Shaw GM, et al.: Analysis of neutralization specificities in polyclonal sera derived from human immunodeficiency virus type I-infected individuals. I Virol 2009, 83:1045-1059.

35. Kuwata T, Byrum R, Whitted S, Goeken R, Buckler-White A, Plishka $R$, lyengar $R$, Hirsch VM: A rapid progressor-specific variant clone of simian immunodeficiency virus replicates efficiently in vivo only in the absence of immune responses. J Virol 2007, 81:8891-8904.

36. O'Neil SP, Suwyn C, Anderson DC, Niedziela G, Bradley J, Novembre F], Herndon JG, McClure HM: Correlation of acute humoral response with brain virus burden and survival time in pig- tailed macaques infected with the neurovirulent simian immunodeficiency virus SIVsmmFGb. Am J Pathol 2004, 164: I |57-I I72.

37. Igarashi T, Brown CR, Endo Y, Buckler-White A, Plishka R, Bischofberger N, Hirsch V, Martin MA: Macrophage are the principal reservoir and sustain high virus loads in rhesus macaques after the depletion of CD4+ $T$ cells by a highly pathogenic simian immunodeficiency virus/HIV type I chimera (SHIV): Implications for HIV-I infections of humans. Proc Natl Acad Sci USA 200I, 98:658-663.
Publish with Bio Med Central and every scientist can read your work free of charge

"BioMed Central will be the most significant development for disseminating the results of biomedical research in our lifetime. "

Sir Paul Nurse, Cancer Research UK

Your research papers will be:

- available free of charge to the entire biomedical community

- peer reviewed and published immediately upon acceptance

- cited in PubMed and archived on PubMed Central

- yours - you keep the copyright

Submit your manuscript here:

http://www.biomedcentral.com/info/publishing_adv.asp 